\title{
From one-shot sessions to embedded librarian Lessons learned over seven years of successful faculty-librarian collaboration
}

S uccessful information literacy programs require collaboration between multiple constituencies, including faculty, staff, administrators, and librarians. The purpose of this article is to share some of the lessons we've learned in our faculty-librarian partnership, in the hope that it might inform and guide others seeking to build successful collaborations as they strive to promote information literacy on their campuses.

Our collaboration began somewhat modestly in 2008 with a traditional oneshot session, overoptimistically designed to teach a class of first year sociology students everything they might need to know about library research. Over the next six years, we shaped, customized, tweaked, and adjusted our approach until we arrived at a fully embedded librarian model. The First Year Experience (FYE) Introduction to Sociology course now includes five hands-on information literacy sessions that use active learning, several additional appearances by the librarian in the classroom, and mandatory one-on-one meetings between each student and the librarian.

The librarian and subject faculty member also worked together to create the syllabus and other course materials, including a handbook for student e-portfolios that are a required component of Alfred University's FYE program. Although the initial impetus for change came from a restructuring of the FYE program, which requires each course to be either writing or information literacy intensive, we have taken our collaboration well beyond the required parameters. Along the way we have seen significant improvement in student research papers. We hope to provide a more comprehensive analysis of our assessment data in a future publication.

\section{Fully embedded team teaching is the gold standard}

The ideal to strive for is a situation in which librarians and teaching faculty are complete equals working together on the content and coverage of the information literacy components of the course. Although this ideal cannot always be reached due to various local constraints, interdisciplinary teams often make for a richer educational experience. By endeavoring to move beyond the traditional one-shot model towards full embeddedness, we demonstrate that information literacy is fundamental to generating and consuming knowledge across all disciplines.

\section{Successful collaboration develops organically over time}

Librarians cannot realistically expect subject faculty to yield massive blocks of class time overnight. Rather, this relationship must

Brian T. Sullivan is information literacy librarian, email: sullivan@alfred.edu, and Karen L. Porter is professor of sociology, email:fporterk@alfred.edu, at Alfred University ๑ 2016 Brian T. Sullivan and Karen L. Porter 
develop naturally over a longer period of time. In our case, we began with a traditional one-shot session.

The next time around, we created a custom activity designed specifically around the students' research assignment. Realizing the need for further instruction, our collaboration then evolved into three and later five sessions, in addition to the one-on-one meetings. Our partnership grew around our shared concern about helping students become successful researchers. Each year as we looked back over our work, we considered ways in which we might better assist students by expanding certain themes and topics, as well as eliminating or reducing others that did not work or turned out to be unnecessary.

\section{Show up early and often}

The more times students encounter the librarian, the better. Appearing in the syllabus and other course documents makes it clear that the librarian and subject faculty member are equal partners in this endeavor. This is essential to making sure students understand that information literacy is an integral part of the course, and not just a supplemental lesson.

We have found that introducing the librarian during the first week of classes, referring to the librarian as "Professor," and allowing the librarian to have an ongoing role is very important for the overall information literacy plan to be successful.

Some ways we have included the librarian beyond the actual information literacy sessions are: having multiple five minute mini-lessons during class, involving the librarian in key class discussions, requiring one-on-one appointments with the librarian, and having the librarian attend universitywide FYE lectures. Although it can be time consuming for the librarian, these need not take up much class time, and will make the information literacy sessions significantly more impactful due to students already having formed a relationship and sense of familiarity with the librarian.

\section{Recognize that information literacy can be time consuming}

Librarians may not want to lead with this point if they are trying to make the case for including more information literacy to faculty, but deep learning can be time consuming. In our work together, we regularly had to face the fact that it was impossible to cover every last facet of introductory Sociology, while meaningfully teaching information literacy. Decisions, sometimes painful, needed to be made about what to include and what to leave out.

Rather than stuffing dozens of learning objectives into rushed (and boring) lectures, we have strived to focus thoroughly on one or two things in each lesson. By breaking down the research process into smaller steps, encouraging mindfulness, and using more active learning, we have seen vast improvements in student comprehension. Along the way we have revealed just how many assumptions we incorrectly made in what students know. For instance, over time, our initial lesson about finding the full text of an embedded reference cited in the textbook grew into multiple lessons about such topics as different types of sources, scholarly versus popular sources, decoding a citation, and using our library's journal locator tool. By uncovering the various steps, and directly addressing our students' comprehension of each, we were better able to help students succeed in their research.

\section{Take meticulous notes}

A fairly rudimentary, but critical lesson we have learned is to take detailed notes about every aspect of your collaboration. Record everything. Before, during, and after each session, write down as much as you can. For instance, keep track of what worked and did not, how the lesson was put together, and what your motivations and intentions were about including or not including various things. This will greatly help you in the future. Even though it seems like you'll remember everything, by the time the next opportunity rolls around in a future 
semester, many of those details will be lost (especially for those who do a lot of teaching with many classes). By keeping track of each lesson and activity, you'll be equipped to make significant improvements with each new iteration.

\section{Experiment freely}

Over the course of seven years, we have tried all sorts of approaches, techniques, and tools in our teaching. Clickers, videos, polling, games, contests, and prizes have all been part of our repertoire. Some of it worked, some did not. Sometimes the success or failure of a lesson or activity was more about the composition, mood, and personality of the students than anything inherent to the session itself. Other times, certain ideas simply did not work. But the only way to discover this is to freely experiment. One of our most successful activities is one in which students try to find the worst, most unreliable source on a sociological topic. We only found this out by trying it out to see what would happen. Successful collaboration requires a sense of humor and a willingness to not take things too seriously. It is a good thing to have some fun with your work. This makes things significantly more interesting for you and your students.

\section{Assess as much as you can in as many ways possible}

Just as it is useful to experiment freely, the other side to this is to assess freely. It is beneficial to assess as much as you can in as many ways possible. Wide variety is the key to gathering a collection of balanced and useful information. In our work together, some of the assessments we used include SAILS (Standardized Assessment of Information Literacy Skills) pre- and posttests, student reflections, information literacy worksheets, analysis of student papers, observations of student activities, and quizzes. There really is no such thing as too much data. Especially when there are two teachers in the room (at times we were fortunate enough to have three counting the peer leader), one person can easily be collecting assessment data while the other teaches. Just as important as collecting all of that information is to then use it to design future lessons and activities that improve student learning. Sometimes this point can be missed in the midst of all of the forms, accreditation processes, top-down initiatives, and grand thoughts about the value of libraries. Assessment is ultimately about being more effective teachers to help students learn.

\section{Be flexible}

Collaborating with subject faculty to teach information literacy to early college students requires a hearty dose of patience and flexibility. Sometimes lessons are not going according to plan and need to be adjusted on the fly. Sometimes assignments need to be modified to allow for the true objectives to be the primary focus. For instance, we came to realize that we needed to drop the research proposal component of the assignment to help students focus their attention on the literature review, which was more essential to our information literacy objectives. Additionally, we need to be flexible from semester to semester so that adjustments can be made. Sometimes our favorite activities did not work and needed to be dropped or modified.

Flexibility is also required to address what students really need, especially when it turns out to differ from what we expected them to need. At times we have been surprised by what students already knew about some aspects of information literacy, such as evaluating resources. At other times, we have been equally surprised by what they did not know, such as the process of how articles get from author to journal to database. Making things more challenging is the reality that many first-year students are overconfident about their research abilities. We have learned to be patient with students' impatience with information literacy.

Over time we have shifted our teaching away from search skills and finding data- 
bases, and focused more on choosing and narrowing topics, concept mapping, and developing search terms. Each of these adjustments has required plenty of flexibility to navigate the balancing act between not assuming students know things about research, while also not insulting them with overly rudimentary information.

\section{Fully integrate information literacy and course material}

When libraries and information literacy are authentically integrated into a course, students realize that it is not a separate module or something that does not require their complete attention. It demonstrates that the subject faculty member values these components and sees them as integral to the course, which students are keenly sensitive to. For students to fully appreciate the information literacy aspects of a course, those aspects need to be a part of the grade, included on the syllabus, and integrated with the course content as much as possible. This requires planning on the part of the librarian and subject faculty member. Some of the ways in which we have worked information literacy into the grading is through quizzes, points for consulting with the librarian, and points for completing the various assessments. We have integrated the course content by making sure our examples, exercises, and activities were relevant to key topics covered throughout the semester. We have also used our ongoing research project as an example for students to model as budding sociologists. For example, we have been transparent about our methods as we research them doing research, and used this transparency to share our process as well as teach topics such as informed consent.

\section{Conclusion}

Librarians should be proactive on their campuses to find collaborators who are interested in exploring ways to teach and evaluate information literacy and focus their attention on cultivating those partnerships. In our case, sociology and information literacy have been a natural fit. Building on our shared interest in improving students' research skills, and applying the lessons above, we have evolved our collaboration from an ineffective traditional one-shot session to a successful fully embedded teamtaught model. ?

"Our powers combined" (continues from page 33)

way. By working in a collaborative manner, we not only provide needed outreach about library and writing center services, but we also help students think critically about how they write and, hopefully, see that research and writing are not separate entities, but integral parts of a larger process. We look forward to further collaboration between the writing center and the library at USU and implementing formal assessment surrounding coteaching opportunities and lesson plan creation.

\section{Notes}

1. Ilka Datig and Luise Herkner, "Get ready for a long night: Collaborating with the writing center to combat student procrastination," College \& Research Libraries News 75, no 3
(2014): 128-31.

2. Leslie Foutch, "Joining forces to enlighten the research process: A librarian and writing studio integrate," College $\&$ Research Libraries News 71, no. 7 (2010): 370-73.

3. Mary O'Kelly, Julie Garrison, Brian Merry, and Jennifer Torreano, "Building a Peer-Learning Service for Students in an Academic Library," portal: Libraries and the Academy 15, no. 1 (2015): 163-82, doi: 10.1353/pla.2015.0000.

4. Karen Bronshteyn and Rita Baladad, "Librarians as Writing Instructors: Using Paraphrasing Exercise to Teach Beginning Information Literacy Students," Journal of Academic Librarianship 32, no. 5 (2006): 533-36, doi:10.1016/j.acalib.2006.05.010. n 